\title{
Behavioral Analysis of Potential Induced Degradation on Photovoltaic Cells, Regeneration and Artificial Creation
}

\author{
Alex Mirtchev $(\mathbb{B}$, Theodoros Mouselinos $\mathbb{(}$, Stylianos Syrigos $(\mathbb{D}$ and Emmanuel Tatakis * \\ Laboratory of Electromechanical Energy Conversion, Department of Electrical and Computer Engineering, \\ University of Patras, 26504 Patras, Greece; a.mirtchev@upatras.gr (A.M.); t.mouselinos@ece.upatras.gr (T.M.); \\ ssyrigos@ece.upatras.gr (S.S.) \\ * Correspondence: e.c.tatakis@ece.upatras.gr; Tel.: +30-2610-996866
}

Citation: Mirtchev, A.; Mouselinos, T.; Syrigos, S.; Tatakis, E. Behavioral Analysis of Potential Induced Degradation on Photovoltaic Cells, Regeneration and Artificial Creation. Energies 2021, 14, 3899. https:// doi.org/10.3390/en14133899

Academic Editor: Teuvo Suntio

Received: 9 June 2021

Accepted: 27 June 2021

Published: 29 June 2021

Publisher's Note: MDPI stays neutral with regard to jurisdictional claims in published maps and institutional affiliations.

Copyright: (c) 2021 by the authors. Licensee MDPI, Basel, Switzerland. This article is an open access article distributed under the terms and conditions of the Creative Commons Attribution (CC BY) license (https:/ / creativecommons.org/licenses/by/ $4.0 /)$.
Abstract: Many photovoltaic (PV) parks suffer from a decrement in their generated power capability due to a phenomenon called potential induced degradation (PID). In this paper, a regenerative system using a high step-up DC-DC converter is proposed, for regenerating PV cells that have been degraded due to the PID effect. The same device also can be used for artificially creating PID on PV panels in order to study the effects of the PID under controlled conditions. The power converter offers multiple voltage levels at the output to adapt to various voltage ratings of PV parks. The device has plug-and-play features, ultra-low cost, small size and is simple in operation. Experimental tests are conducted in real PV panels and comparative results verify the operational principles of the proposed system. The artificial creation of the PID phenomenon and the regeneration of the PV cells are successfully proven experimentally.

Keywords: AC-DC converters; high voltage power converters; photovoltaic cells; PV degradation; renewable energy sources

\section{Introduction}

In the last few decades, energy harvesting from renewable energy sources has been growing rapidly, as a result of increased fossil fuel costs and increased power demand. However, the growing environmental problems are a serious concern in our society, which must not be neglected. Solar and wind energy are the two types of renewable energy sources that concentrate the biggest interest for clean energy generation. More specific, solar energy is gaining more and more attention and the photovoltaic (PV) power injection to the utility grid is growing, since it offers many advantages, such as [1,2]:

- $\quad$ Solar energy is a non-exhaustible energy source.

- PV cells now offer increased power conversion efficiency and low cost.

- $\quad$ Energy conversion can be achieved without extra pollution.

- $\quad$ PV cells produce maximum power during midday, when the power demand reaches its peak value.

For all these reasons, large-scale, high-power PV plants are being implemented, ranging from tens of kilowatts up to several megawatts [2]. Although PV plant technology is growing rapidly, there are some problems that can cause severe power loss. The most common problems reported in PV plants (at the PV panel level) are the hot spots on the PV panels and the potential induced degradation (PID) effect [3].

By the term hot spot, we refer to the PV cells within the PV panel, which are characterized by an increased temperature value. The main reasons that can cause hot spots in PV panels are the mismatched PV cells' electrical characteristics, the partial shadowing of the panel and the microcracks. When $\mathrm{n}$ series-connected cells supply a load while one or more cells are damaged (or shadowed), they consume a part of the generated power. The power consumed by the faulty cells is converted to heat, causing a rise in their temperature. 
This power loss can be limited in practice by connecting bypass diodes in parallel from twelve to twenty-four cells [4].

Another problem that can affect the power generated from PV panels is the PID effect, where the energy generated from a PV plant is decreased when the PID effect is present $[4,5]$. This problem is caused to PV panels, which are feeding the grid with active power, by using non-isolated inverters. The eliciting factor of the PID effect is the high voltage difference between the PV cell and the aluminium frame of the PV panel, due to the high number of series-connected panels and the inability of earth-grounding one of the output terminals of the string [6,7]. The presence of a strong electric field between the PV cell and the aluminium frame, which is earth-grounded, causes an electron leakage [8,9]. This phenomenon can be recognized either by the thermal imaging of the PV panel or by measuring its electrical values (voltage and current) under load. From the literature, it is deduced that the PID effect is a reversible phenomenon if it is diagnosed and treated in its first stages [10]. Nonetheless, there are cases where the PID effect may cause irreversible damage to the PV panel, as presented in [11].

To deal with the degradation of PV panels, various methods have been proposed, some related to the prevention of the PID phenomenon, while others to revert its effects. The PID appears in PV arrays where there is an inability to connect the negative or positive pole of the array (depending on the cell type) to the earth-ground. Therefore, the use of electronic devices that allow the earth-grounding of the PV panel is a good solution that can be applied in advance when building a PV unit. For example, power converters with galvanic isolation [12] or advanced converters without isolation that allow the PV panel terminals to be earth-grounded [13] are ways to prevent the degradation. This, however, requires particular system specifications and is not always feasible. On the other hand, at the microscopic level, an alternative way to prevent the PID is to use specific PV cells and frames (glass surface, anti-reflective coating, etc.) that have a special molecular structure, with the advantage that they do not leak e- or they have a significantly reduced leakage current $[14,15]$. This solution, like the previous one, may have limitations and increased cost in case of replacement of the existing units in a photovoltaic park. Thermal recovery is another way to solve the PID problem [10]. Storing PID-affected PV panels in chambers with a temperature around $100^{\circ} \mathrm{C}$ leads to the recovery of the PV panel, but it causes high stress on the panel materials, which may affect their overall lifetime. The subjection of the PID-affected panel to UV exposure reverses the phenomenon. Both solutions require special infrastructure. Another method for solving the PID phenomenon is the biasing of the PV cells with a high voltage, with a polarity opposite to the voltage causing the phenomenon. Specifically, a high voltage can be applied between the cell and the frame [16] or by using corona discharge [10,17]. Commercial products, such as in [18-20], apply high voltage to PV panels to deal with PID problems that already exist, but the complexity of their power conversion stage is unknown. However, to the best knowledge of the authors, there is no specific power electronics converter solution described in the literature for the given application.

In this paper, a comprehensive solution for regenerating PV cells affected by PID is proposed. A simple and low cost high step-up power electronics converter, based on the Cockroft-Walton voltage multiplier, is implemented, with the ability to treat and artificially create PID for research purposes. The converter can provide a four-step variable DC voltage, which is useful for research purposes when the rate of the PID effect development is investigated. Moreover, with a portable plug-and-play device, compatible with communication protocols, the PID effect can be studied without the relocation of the PV panels. The rest of the paper is organized as follows. In Section 2, the operational principals of the PID and the proposed regenerative method are presented. In Section 3, the power converter, deployed for the high voltage generation, is analyzed, along with all the power conversion stages. In Section 4, the experimental validation of the implemented device is presented in a standalone operation and with actual PV panels. Section 5 concludes the paper. 


\section{Regeneration of Photovoltaic Cells}

In this section, a simple and comprehensive explanation of the PID effect is given. As already described in Section I, PID is a reversable phenomenon and there are different methods to encounter it. The suggested method is by utilizing a power converter that can be externally connected to multiple PV panels, even if they are already installed in a photovoltaic park. By regenerating the PV cells, the maximum output power is increased, by restoring the open circuit voltage, the short-circuit current and the maximum power point (MPP), close to their nominal values.

\subsection{Potential Induced Degradation on $p$-Type \& n-Type Cells}

The PV cells that make up a PV panel are divided into two categories depending on their structure. Based on the type of semiconductor used as a base for their construction, a PV panel can be either p-type or n-type. The PID effect occurs in both cases but under different conditions [9]. Therefore, it is necessary to either know the structure of the cells or to be able to determine it experimentally, as will be analyzed below.

During normal operation, the electrons accelerate towards the $n+$ region, under the influence of the potential barrier between the p-n contact and the holes towards the p+ region. In Figure 1, the cross-section of a p-type PV panel is illustrated. The group of cells are supported on an aluminum base and covered by a glass surface and an anti-reflective coating, which reduces the reflected radiation. The PID effect occurs when a positive charge, such as sodium cations $\left(\mathrm{Na}^{+}\right)$, settle on the glass surface. Photons produced by solar irradiation fall on the p-type semiconductor of the cell, creating holes $\left(\mathrm{h}^{+}\right)$and electrons $\left(\mathrm{e}^{-}\right)$. In the event that a positive charge has accumulated on the surface (e.g., silicon dioxide $\left.\left(\mathrm{SiO}_{2}\right)\right)$ and on the anti-reflective coating (e.g., silicon nitride $\left.\left(\mathrm{Si}_{3} \mathrm{~N}_{4}\right)\right)$, the electrons are attracted to the glass surface, or otherwise the holes are directed to the $\mathrm{p}^{+}$region. Charge accumulation can be represented by equivalent capacitors between the cells and the glass [21], as shown in Figure 1. As a result, there is leakage of electrons to the earth-ground, meaning that the conventional direction of the current is from the earth-ground towards the frames. As a consequence, a negative potential difference between the cells and earthground is developed [9]. This bias effect is intensified by high humidity, which reduces the impedance between the glass surface and the aluminum support frame, increasing the leakage current. The aluminum frame is naturally connected to the earth-ground. The cells that are most affected by this phenomenon are those closest to the negative pole of the DC voltage, where the voltage potential with respect to the earth-ground is higher $[4,5]$.

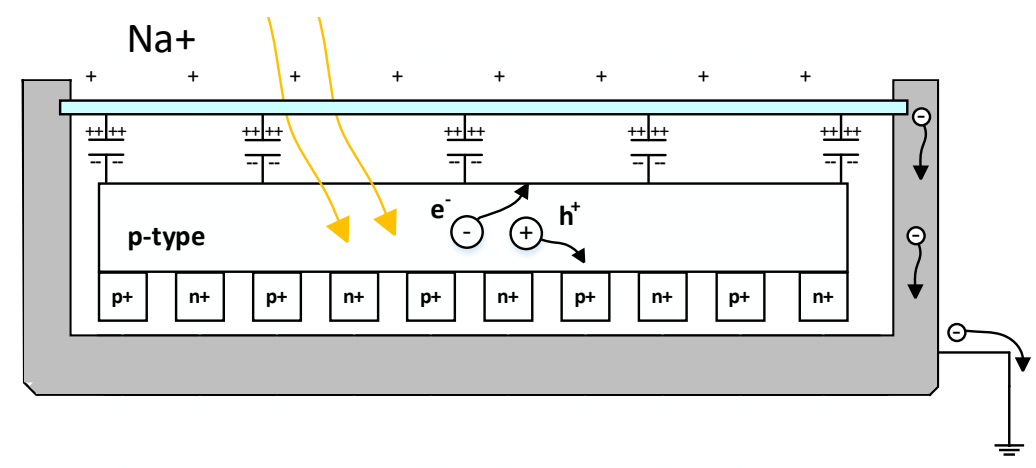

Figure 1. A cross-section of a p-type PV panel that is losing electrons due to PID.

If the PV cells are constructed with n-type semiconductors, the occurrence of the PID phenomenon is similar with the p-type cells that was previously described. In Figure 2, a representative example is shown, where a negative charge has accumulated on the glass surface, creating a parasitic capacitance. A positive potential with respect to the earthground is now present. As shown in Figure 2, the leakage is opposite to the previous case and the phenomenon is more intense at the cells towards the positive pole of the output voltage [9]. 


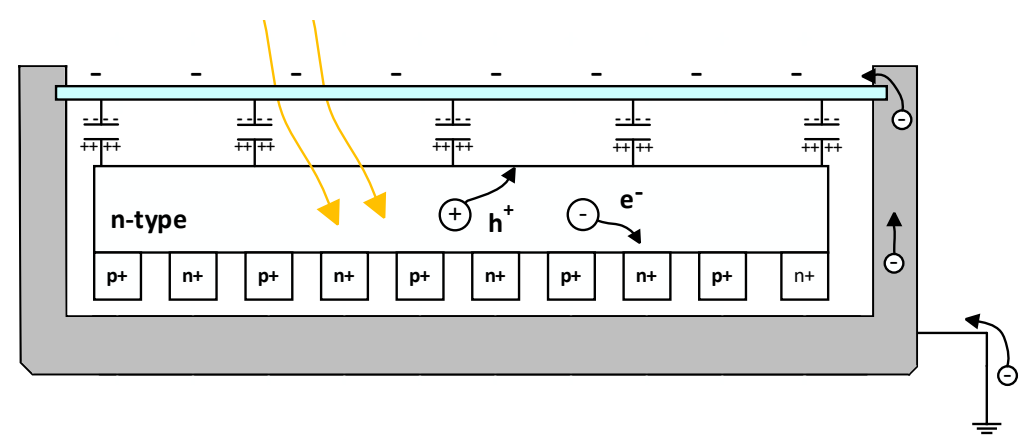

Figure 2. A cross-section of an n-type PV panel that is losing electrons due to PID.

In any case, by short-circuiting the output of the PV panels, it is possible to detect the potential difference by measuring the voltage between this common point with the aluminum support frame. In this way the cell type is identified.

\subsection{Regeneration with a Power Converter}

As mentioned earlier, the reverse of PID effect can be achieved with the use of a power electronics converter. A high DC voltage is applied between the PV panel output and the aluminum support frame, which is directly connected to the earth-ground, as shown in Figure 3. The polarity of the voltage is the opposite of that which causes the degradation phenomenon. This way, the potential of the PV panel relative to the earth-ground is raised, and the leakage current is eliminated by reversing the flow of electrons back to the PV cells. The voltage amplitude should not exceed the maximum system voltage, as defined by the manufacturer of the PV panel. The device can operate when there is no energy production, either during the night or if the panels are manually and totally shaded [17]. The regeneration process even can be speeded-up, if the glass surface is damp, since the impedance of the escape path of the e- is reduced [9].

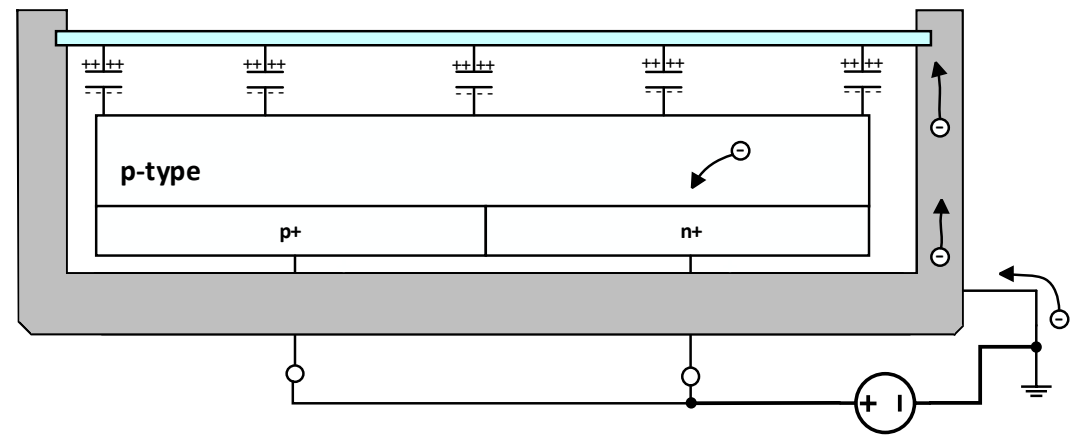

Figure 3. A cross-section of a p-type PV panel that is biased with the power converter where the regeneration is implemented.

Our goal is not only to reverse the PID effect on the panels, but also to create a device that can be installed easily and at any environment, that can be applied to any type of cells (p-type or n-type), and that is simple and safe to use. In a PV park, the outputs of the PV array are short-circuited during the regeneration, while the main inverter is disconnected from the grid.

The PID effect on p-type cells does not occur when the voltage applied by the converter is positive. Therefore, there is no risk of causing any damage to the PV panels due to prolonged polarization of the array. This automatically provides safety to the system and reduces the complexity of the power converter control. The converter can be connected to multiple PV arrays that are parallelly connected, so that they are polarized with the same voltage. 


\subsection{Artificial Creation of PID on PV Panels}

As already mentioned, the PID phenomenon is evolving slowly and its effects are becoming apparent in the long run. To study the problem and analyze the effects and the damages it causes on PV panels, an easy method to artificially create PID on PV panels under controlled conditions is proposed. By utilizing the same power converter that is used for the regeneration of the PV cells and reversing the output voltage, the electric field that causes the leakage of electrons is applied to the panel. In Figure 4, an example of artificially creating PID is depicted, where the power converter is connected in reverse, compared to Figure 3, and the flow of electrons is forced in such a direction so as to degrade the PV cells. A positive charge has accumulated on the glass surface as a result, just like the naturally occurring phenomenon shown in Figure 1.

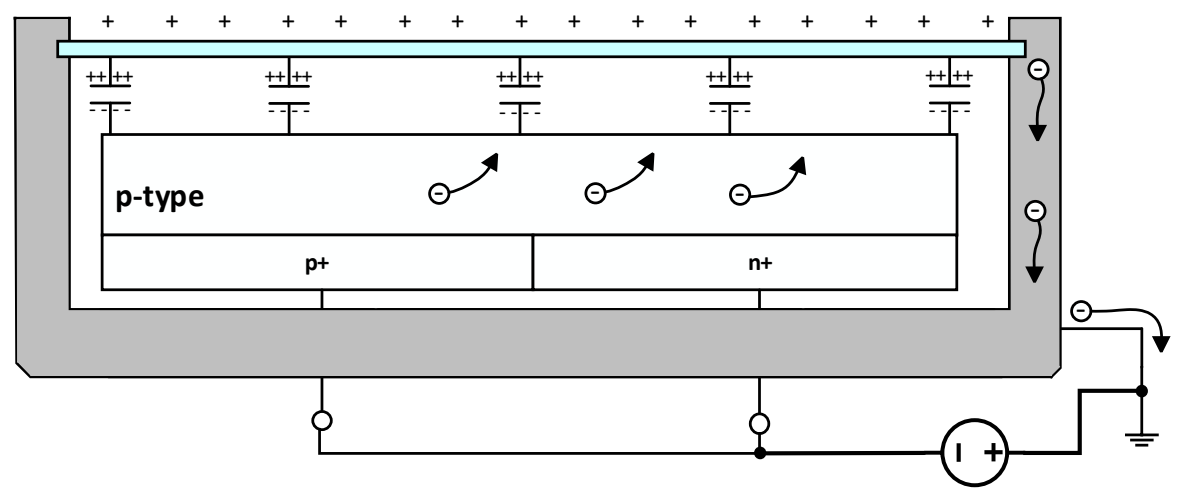

Figure 4. A cross-section of a p-type PV panel when degradation is implemented by the power electronics converter.

Compared to the other solutions mentioned in Section 1, the proposed method offers many advantages: not only it is a low cost solution, but, also, there is no need for special equipment to generate a high voltage and place cations on the glass surface; the device is portable and can be tested anywhere, by simply shading the panel surface; and multiple panels can be connected in parallel or in series for mass testing.

\section{Power Converter Description}

The main requirements of the power electronics converter in this application is to produce a high DC voltage at light load conditions (due to the low leakage currents), the ability to use low rating semiconductor devices to cut down the cost and to simplify the control of the output voltage. What is more, since high accuracy of the converter output voltage level is not a strict requirement, the converter is designed to generate four discrete voltage levels. As the device features a plug-and-play operation, a pre-charge circuit is used for the start-up when the mains utility voltage of $230 \mathrm{~V} / 50 \mathrm{~Hz}$ is connected. The galvanic isolation is also a requirement to prevent unexpected short circuits, since the neutral of the power distribution network and the DC output of the converter are both earth-grounded.

The power converter used for generating a high DC voltage is based on the CockroftWalton voltage multiplier (CW-VM). The CW-VM topology is selected for this application, since it offers many advantages, such as the use of semiconductor devices and capacitors with low ratings, since the maximum theoretical voltage of the switching devices and the capacitors is equal to the double of the peak input voltage at the worst-case scenario.

The voltage gain of the CW-VM with $\mathrm{n}$ stages can be calculated by (1) (without load), in which $E_{\mathrm{pk}}$ is the peak value of the input voltage and $V_{\mathrm{o}, \mathrm{nl}}$ is the mean value of the non-loaded output voltage [22]. In this application, the output current of the converter does not exceed the magnitude of some mA (or less); therefore, the voltage drop of the 
output can be neglected. Even more, due to the nature of the application, there are no abrupt changes in the load that can affect the converter output voltage.

$$
X_{\mathrm{nl}}=\frac{V_{\mathrm{o}, \mathrm{nl}}}{E_{\mathrm{pk}}}=2 \cdot n
$$

As described in [22], a voltage ripple across the capacitors of the topology is present under load. This voltage ripple can be very high if the frequency of the AC voltage source supplying the CW-VM is low. Taking into consideration that the utility grid has a frequency equal to $50 \mathrm{~Hz}$, there are two solutions for limiting the voltage ripple. The obvious solution is to increase the total capacitance of the $\mathrm{CW}$-VM, and the second solution is to feed the voltage multiplier with a high frequency AC voltage. In this paper, the second solution is adopted to decrease the total volume of the device. To do so, a Half-Bridge inverter is used to produce the high frequency AC voltage required [23]. The significant advantage of the proposed topology is the simplicity of the control. Specifically, the frequency and the duty cycle of the Half-Bridge are kept constant and the adjustment of the output voltage is implemented using a relay network connected to the CW-VM outputs.

Specifically, the mains voltage is stepped down with the use of a transformer to provide a $144 \mathrm{~V} / 50 \mathrm{~Hz}$ voltage. Then, a rectifier with filtering capacitors is used to produce a smooth DC voltage for the DC/AC conversion stage. The final power conversion stage is the voltage multiplication stage. The stepped down voltage is necessary for the CW-VM to produce five different voltage levels at the output, ranging from approximately $200 \mathrm{~V}$ to $1000 \mathrm{~V}$, with steps of $200 \mathrm{~V}$. The output voltage level can be selected by controlling the state of the relays connected at the output of Stage 2-Stage 5 of the CW-VM. The total converter topology is depicted in Figure 5.

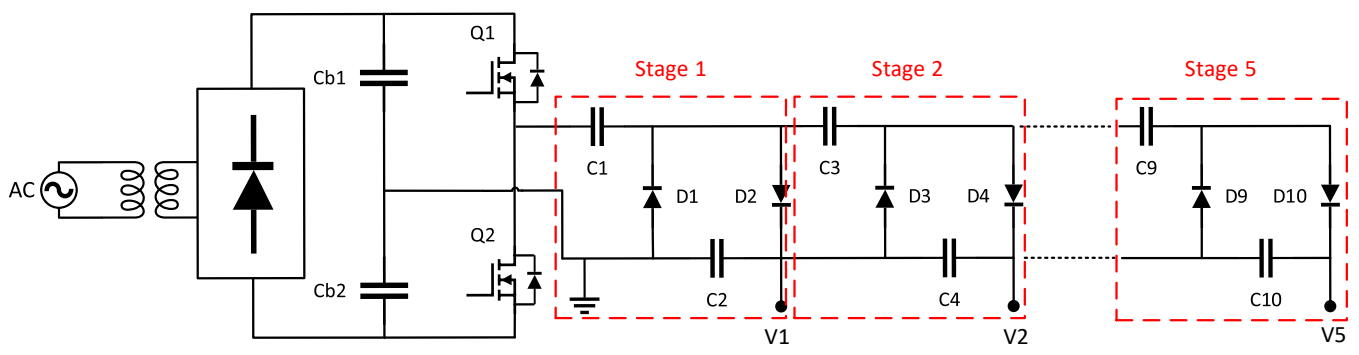

Figure 5. Final AC/DC converter topology with all conversion stages.

To verify the operation of the proposed converter, some indicative simulation results are presented in Figure $6 \mathrm{a}, \mathrm{b}$. The Half-Bridge capacitances were chosen solely based on the desired voltage ripple $C_{\mathrm{b} 1}=C_{\mathrm{b} 2}=94 \mu \mathrm{F}$ and each CW-VM capacitance $C \mathrm{i}(\mathrm{i}=1,2, . ., 10)$ is equal to $12 \mu \mathrm{F}$, with the load current been equal to $5 \mathrm{~mA}$. The semiconductor switches $Q_{1}$ and $Q_{2}$ are controlled with complementary pulses with a frequency of $20 \mathrm{kHz}$.

As can be seen from Figure $6 \mathrm{a}$, a small voltage drop is noticeable due to the operational properties of the CW-VM compared to (1) [22]. What is more, from Figure $6 \mathrm{~b}$ is deduced that the voltages across the capacitors $C_{\mathrm{b} 1}$ and $C_{\mathrm{b} 2}$ are not equal. This can be easily explained if the single stage CW-VM topology is considered. When the $Q_{2}$ transistor is $\mathrm{ON}$, the capacitor $C_{\mathrm{b} 2}$ is connected in parallel with capacitor $C_{1}$. In the time interval in which the $Q_{1}$ transistor is $\mathrm{ON}$, the capacitor $C_{\mathrm{b} 1}$ is in parallel with the series connection of capacitors $C_{1}$ and $C_{2}$. Following a similar logic, it can be deduced that the effective capacitance at the positive half-cycle of the DC/AC stage is smaller compared to the effective capacitance of a negative half-cycle. Hence, the voltage across capacitor $C_{\mathrm{b} 2}$ is lower. 


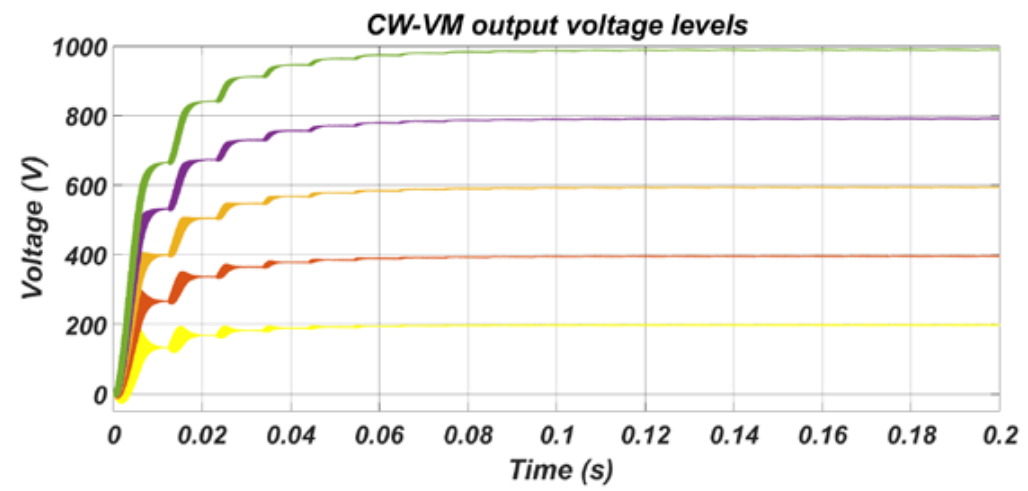

(a)

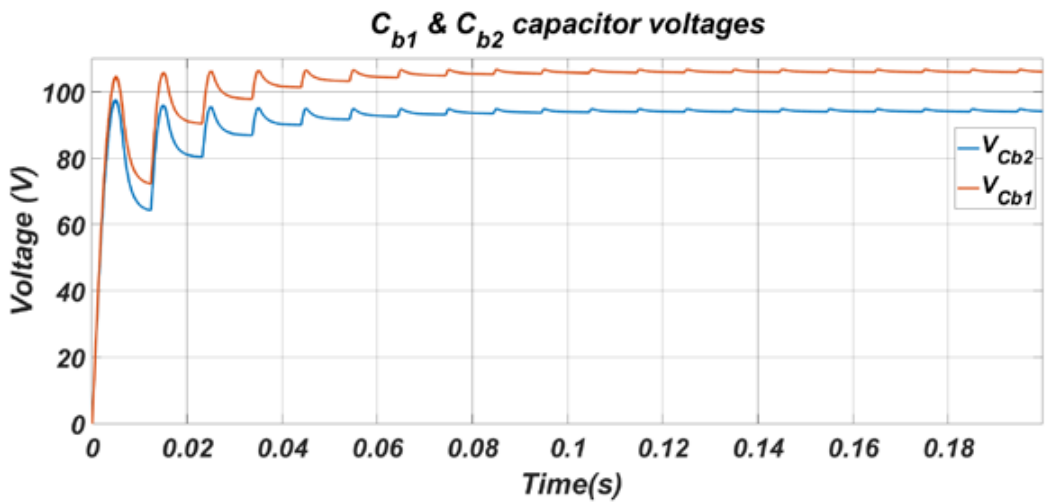

(b)

Figure 6. Key waveforms of the AC/DC converter: (a) CW-VM output voltage levels; and (b) DC bus capacitors voltages.

As described, the power electronics converter is designed to be supplied by the utility grid $(230 \mathrm{~V} / 50 \mathrm{~Hz})$. For long-term and reliable operation, the electrolytic capacitors at the output of the rectifier must be soft charged to limit the high inrush current. There are several ways to provide a soft charging for the smoothing capacitors. The pre-charge circuit used in our application is depicted in Figure 7, which is an improved version of the pre-charge circuit reported in [24], to speed up the initial charging process of the capacitors $C_{\mathrm{b} 1}$ and $C_{\mathrm{b} 2}$, especially for cases where the input voltage comes from the rectified mains voltage. The $C_{\mathrm{DCbus}}$ capacitor is the series combination of $C_{\mathrm{b} 1}$ and $C_{\mathrm{b} 2}$.

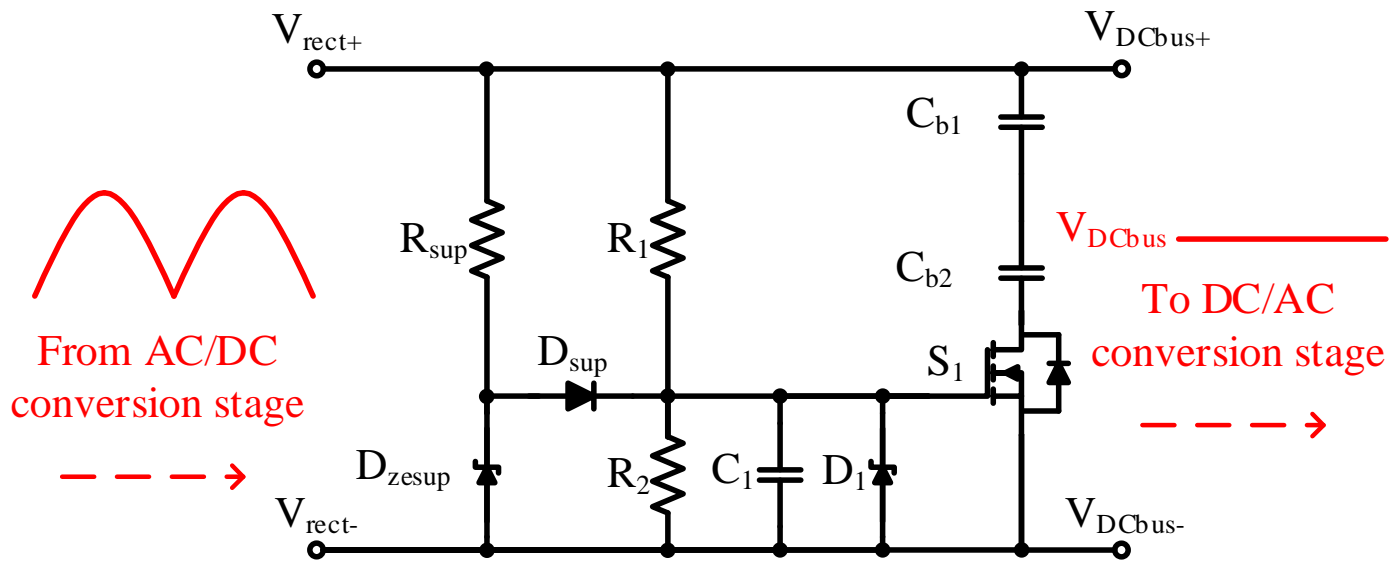

Figure 7. The pre-charge circuit used to soft charge the capacitors of the DC bus. 
The simulation results of the pre-charge circuit are shown in Figure 8. Specifically, in Figure 8a, the DC bus voltage along with the drain-source voltage $V_{\text {DS }}$ of the $S_{1}$ transistor are shown, whereas in Figure $8 \mathrm{~b}$ the gate-source voltage $V_{\mathrm{GS}}$ of the transistor is presented. The effects of the additional circuitry $\left(R_{\text {sup }}, D_{\text {sup }}\right.$, and $\left.D_{\text {zesup }}\right)$ can been noticeable up to $80 \mathrm{~ms}$, where the $S_{1}$ gate-source is speeded-up, up to a value close but below the transistor threshold voltage.

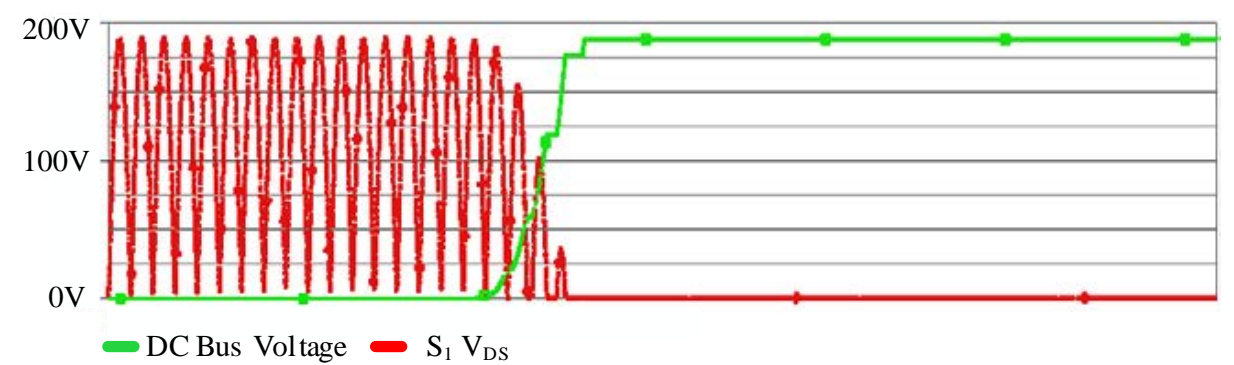

(a)

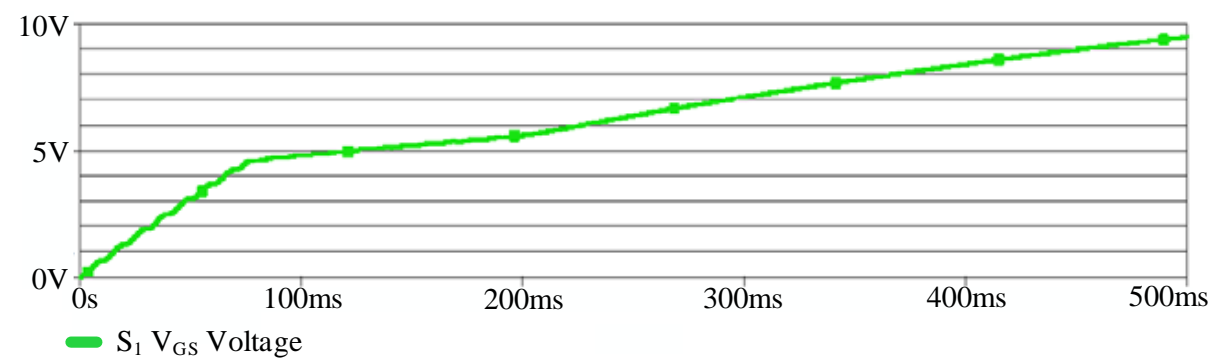

(b)

Figure 8. Indicative waveforms of the pre-charge circuit for the DC bus capacitors: (a) $V_{\mathrm{DS}}$ voltage of the $S_{1}$ switch along with the DC bus voltage; and (b) $V_{\mathrm{GS}}$ voltage of the $S_{1}$ switch.

\section{Experimental Validation}

The proposed power converter was implemented and tested on real photovoltaic panels, in order to validate both the artificial creation of the PID phenomenon and the regeneration of the PV cells. It is a plug-and-play device, with output voltage and current measurements as well as overvoltage and overcurrent protection features. First, the device was tested separately, to verify its operation and its plug-and-play capability. Next, the PID phenomenon was artificially created on one PV panel, while another healthy one was used as the "control panel", serving as a reference point for comparison before and after the PID. After degrading the PV cells of the selected panel for 2 weeks, the regeneration process followed for the same time period. Measurements of the characteristic P-V and I-V curves of both panels were taken along the process. The durability and the operational principles of the device were successfully verified.

\subsection{Experimental Prototype}

An experimental prototype device based on the Cockroft-Walton voltage multiplier topology was designed and implemented. In Figure 9, the power circuit (red PCB) and the control board (blue PCB) are shown. The detailed characteristics of the power converter are given in Table 1 . The different stages of the output voltage make this device adaptable in a wide variety of systems with different characteristics. 


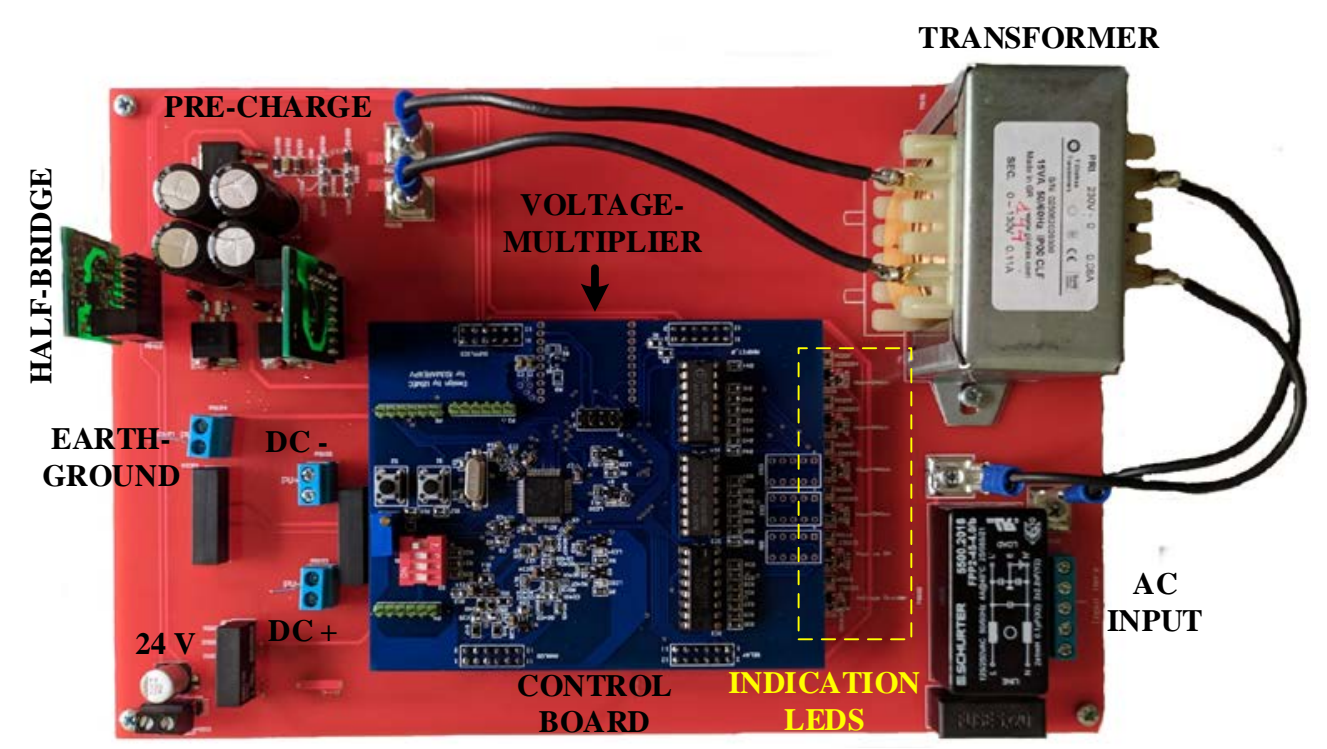

Figure 9. Power converter device for PID emulation and regeneration of PV cells.

Table 1. Converter design specifications.

\begin{tabular}{ccc}
\hline Symbol & Description & Value/Model \\
\hline$V_{\mathrm{in}, \mathrm{AC}}$ & Supply AC Voltage & $230 \mathrm{~V} / 50 \mathrm{~Hz}$ \\
$n$ & Transformer Voltage Ratio & $230 / 144$ \\
$E_{\mathrm{pk}}$ & Cockroft-Walton Input Peak Voltage & $100 \mathrm{~V}$ \\
$V_{\mathrm{o}, \mathrm{nl}, 2}$ & Output Voltage of Stage 2 non-loaded & $370 \mathrm{~V}$ \\
$V_{\mathrm{o}, \mathrm{nl}, 3}$ & Output Voltage of Stage 3 non-loaded & $580 \mathrm{~V}$ \\
$V_{\mathrm{o}, \mathrm{nl}, 4}$ & Output Voltage of Stage 4 non-loaded & $770 \mathrm{~V}$ \\
$V_{\mathrm{o}, \mathrm{nl}, 5}$ & Output Voltage of Stage 5 non-loaded & $965 \mathrm{~V}$ \\
$P$ & Power Rating & $10 \mathrm{~W}$ \\
$C_{1}-C_{10}$ & CW-VM Capacitors & $12 \mu \mathrm{F}$ \\
$C_{\mathrm{b} 1}, C_{\mathrm{b} 2}$ & DC bus capacitors & $94 \mu \mathrm{F}$ \\
$Q_{1}-Q_{2}$ & Half-Bridge MOSFETs & IXTA12N50P \\
\hline
\end{tabular}

The desired output is selected via a DIP-switch and the active output stage $\left(V_{\mathrm{o}, 2}\right.$, $\left.V_{\mathrm{o}, 3}, V_{\mathrm{o}, 4}, V_{\mathrm{o}, 5}\right)$ is indicated with on-board LEDs when the corresponding relay is closed. There are also LEDs that indicate when the relays, which short-circuit the PV terminals $\mathrm{PV}+$ with PV-, and the voltage measurement divider are turned on. The latter is very important, because if the device is constantly connected to the PV panel, it can monitor the reverse voltage that is caused due to the PID effect between the PV- and the earthground. However, the voltage divider placed between these terminals for measuring causes additional leakage when the PV cells are not regenerated, enhancing the leakage of electrons. Therefore, when only monitoring the PV panel and the power circuit is off, the voltage of the PV with respect to earth-ground is discontinuously sampled by switching on and off the corresponding relay, instead of constantly measuring it. The output current was also measured; however, its value is extremely small, since the output impedance is very high and mainly of capacitive nature. Despite that, both voltage and current measurements were obtained during operation and send via UART communication to a computer for evaluation.

Two almost identical and healthy/undamaged PV panels were used in the experiments. In Table 2, the detailed ratings of each panel are given. The second panel $\mathrm{PV}_{2}$, which has slightly higher characteristics in power, voltage and current, was selected as the test subject for the PID phenomenon. This was chosen to ensure that any degradation of the electrical characteristics of its output, compared to the "control panel" $\mathrm{PV}_{1}$, would be due to the PID effects. In Figure 10, the experimental setup of the PV panels installed on the rooftop of our laboratory is shown. The PV panels were shaded during the artificial 
creation of the PID phenomenon and when regenerating the PV cells. The PID device was enclosed in a waterproof box to be protected while being installed under the PV panels.

Table 2. Photovoltaic panels' characteristics.

\begin{tabular}{cccc}
\hline \multicolumn{2}{c}{ PV Panel 1 (p-Type) } & \multicolumn{1}{c}{ PV Panel 2 (p-Type) } \\
\hline$P_{\max , 1}$ & $235 \mathrm{~W}$ & $P_{\max , 2}$ & $240 \mathrm{~W}$ \\
$V_{\mathrm{mpp}, 1}$ & $29.6 \mathrm{~V}$ & $V_{\mathrm{mpp}, 2}$ & $29.8 \mathrm{~V}$ \\
$I_{\mathrm{mpp}, 1}$ & $I_{\mathrm{mpp}, 2}$ & $8.08 \mathrm{~A}$ \\
$V_{\mathrm{oc}, 1}$ & $7.95 \mathrm{~A}$ & $V_{\mathrm{oc}, 2}$ & $37.4 \mathrm{~V}$ \\
$I_{\mathrm{sc}, 1}$ & $37.1 \mathrm{~V}$ & $I_{\mathrm{sc}, 2}$ & $8.63 \mathrm{~A}$ \\
$V_{\mathrm{sys}, \max , 1}$ & $8.56 \mathrm{~A}$ & $V_{\mathrm{sys}, \max , 2}$ & $1000 \mathrm{VDC}$ \\
\hline
\end{tabular}

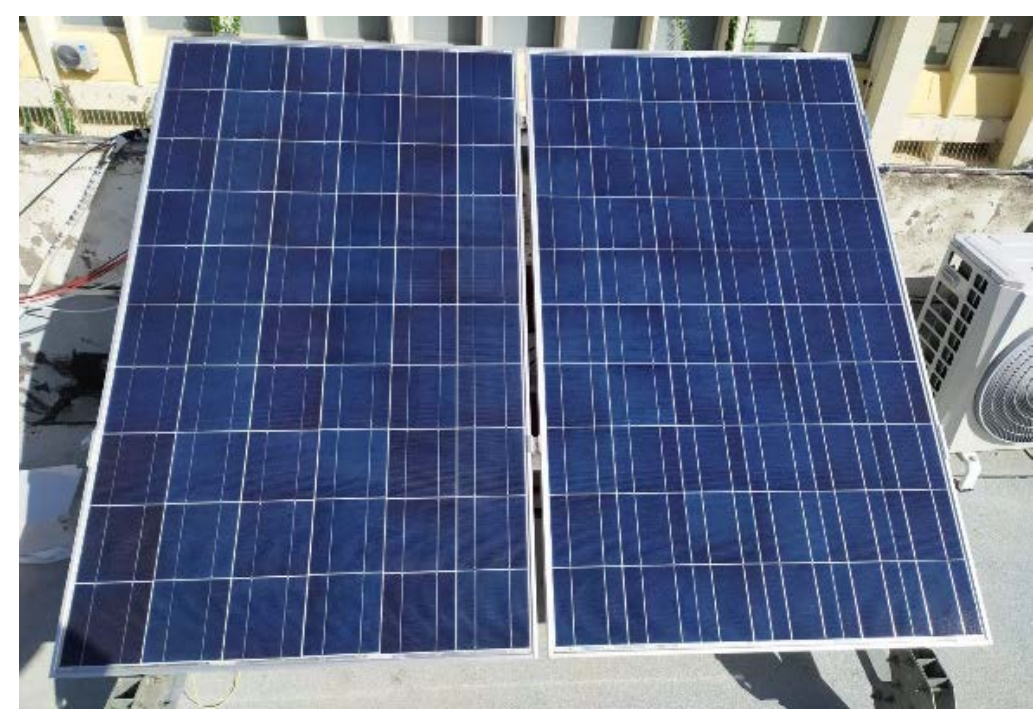

Figure 10. Photovoltaic panels $P V_{1}$ and $P V_{2}$ used for the experiments.

\subsection{Experimental Results}

First, the converter was tested in a laboratory environment, to examine its behavior during start-up, as well as in the steady-state operating point. In Figure 11, the input DC bus capacitors voltage $V_{\mathrm{C}, \mathrm{DCbus}}$ is depicted, along with the DC bus voltage, during startup. The effectiveness of the pre-charge circuit is verified, and a gradual charging of the capacitors is accomplished. As can be seen from Figure 11, the MOSFET used for the pre-charge initially is in the cut-off state; then, as the DC capacitor voltage is raised, the MOSFET enters the saturation region; and finally, when the DC bus capacitors are fully charged, MOSFET enters the linear region. Moreover, in Figure 12, the input current of the grid-side is depicted, when plugging the device into the grid and no significant current overshoot is noted. In Figures 13-16, the voltage transients of all output stages during start-up are shown. There is no voltage spike detected on the output voltages in any of the stages; thus, the start-up of the converter is smooth. In Figure 17 the unequal voltages of the input DC capacitors of the Half-Bridge are depicted, as was expected from the simulation results (Figure 6b). In Figure 18, a ripple voltage of $0.3 \%$ for the maximum output level is shown, which is more than acceptable in our application. 


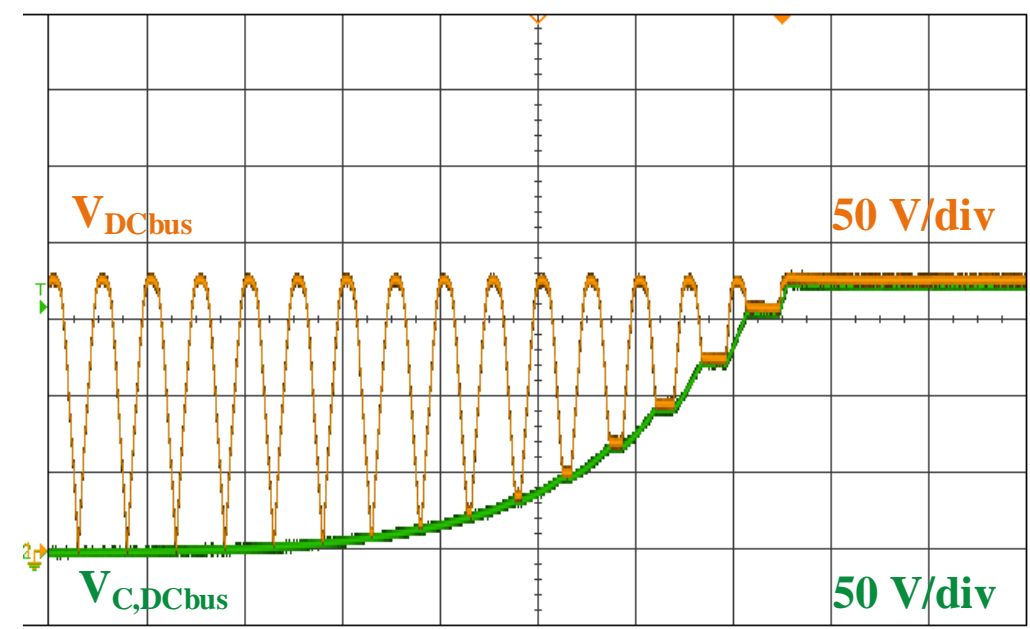

Figure 11. DC bus voltage $V_{\mathrm{DC} \text {,bus }}$ (yellow) and the DC bus capacitors voltage $V_{\mathrm{C}, \mathrm{DCbus}}$ (green) during start-up.

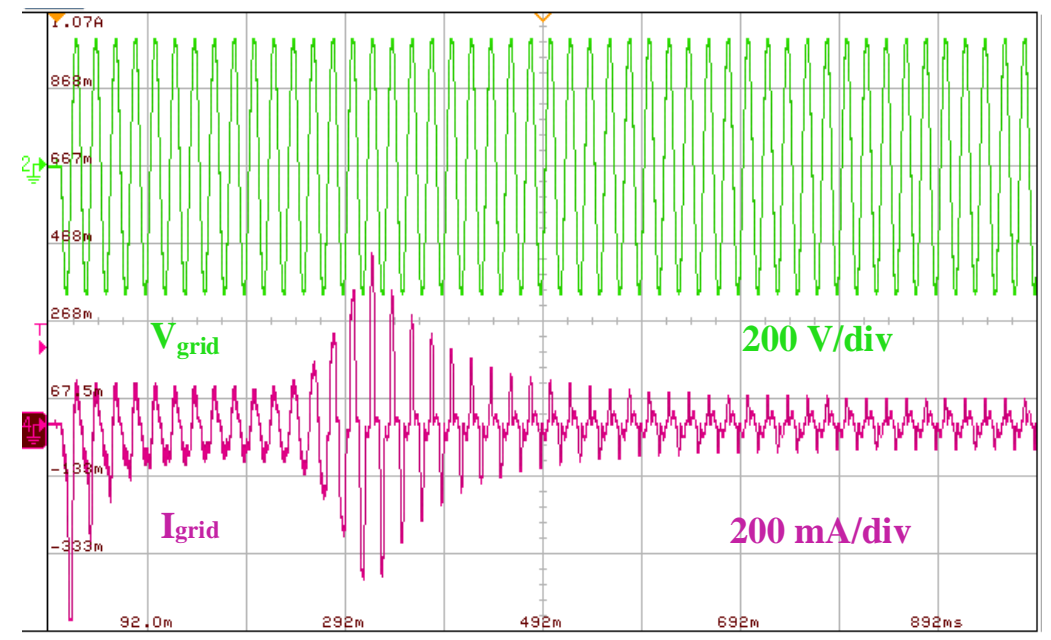

Figure 12. Grid voltage $V_{\text {grid }}$ (green) and grid current $I_{\text {grid }}$ (purple) during the start-up.

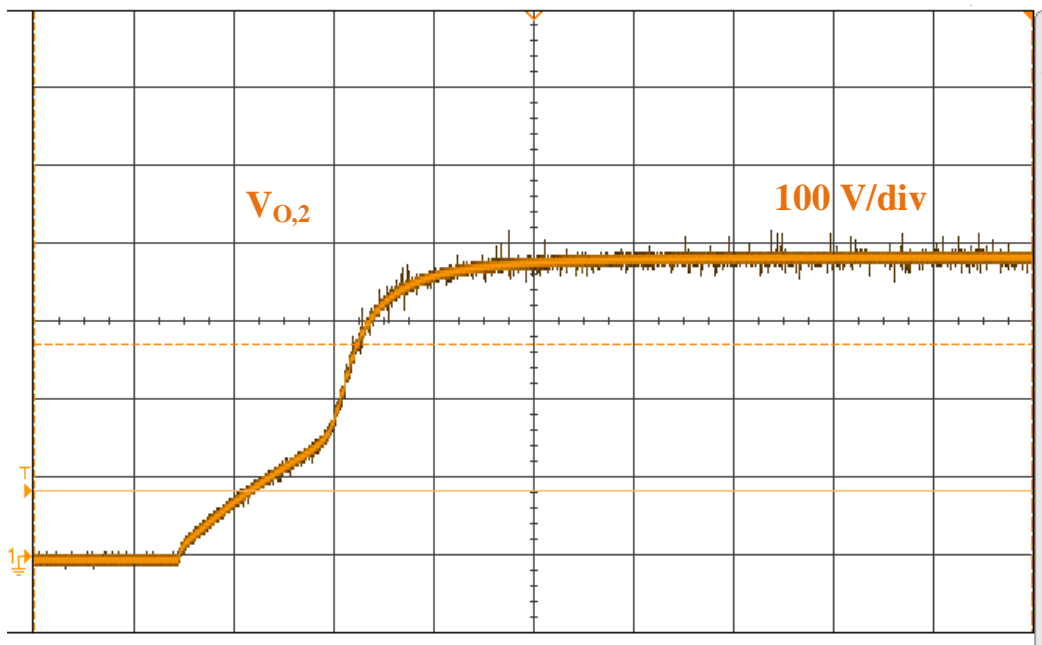

Figure 13. Output voltage $V_{\mathrm{o}, 2}$ of stage 2 . 


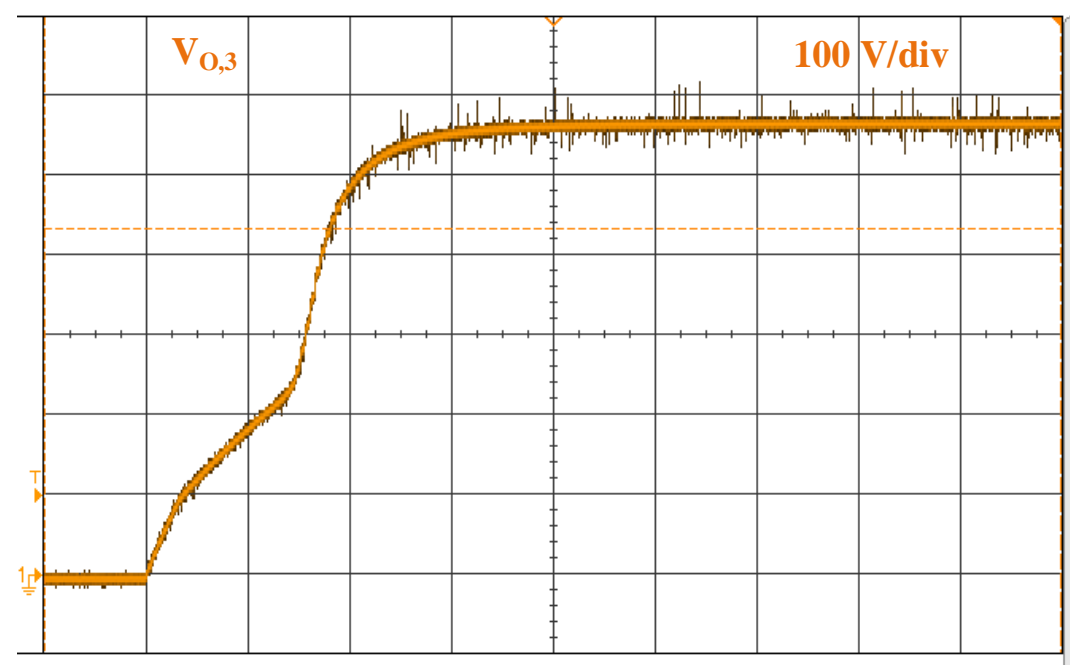

Figure 14. Output voltage $V_{\mathrm{o}, 3}$ of stage 3 .

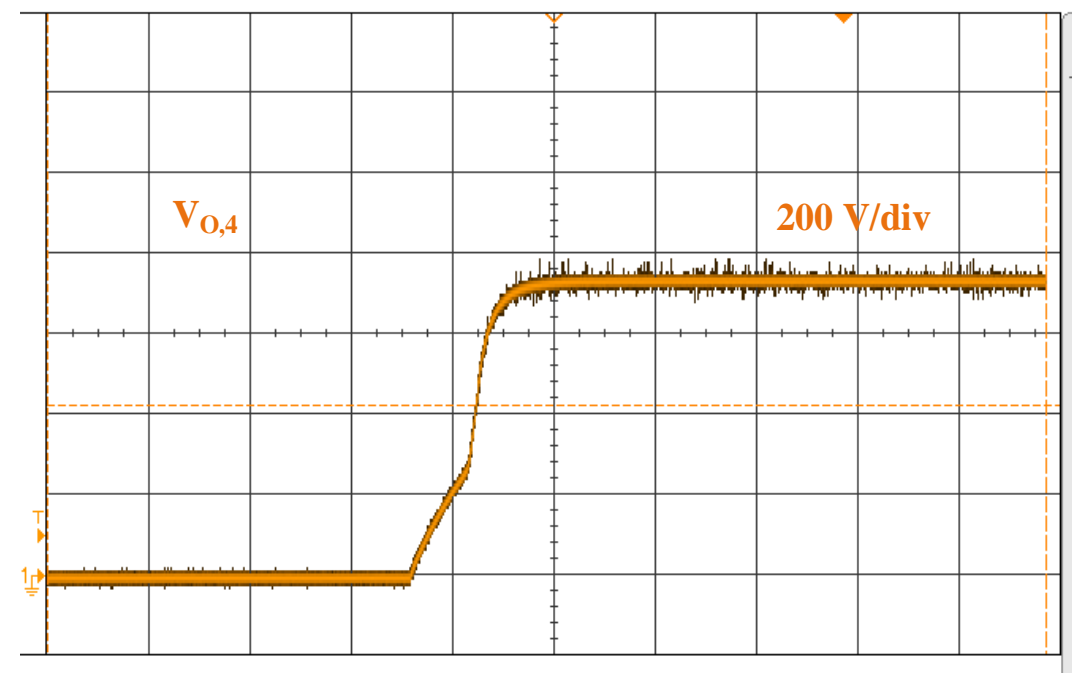

Figure 15. Output voltage $V_{\mathrm{o}, 4}$ of stage 4 .

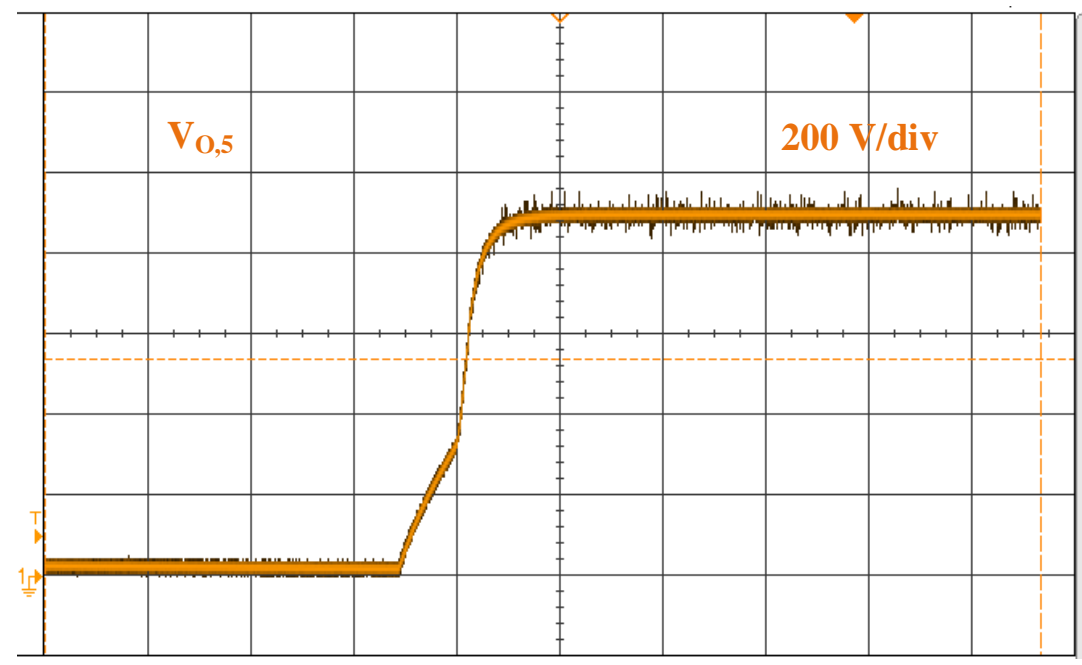

Figure 16. Output voltage $V_{\mathrm{o}, 5}$ of stage 5 . 


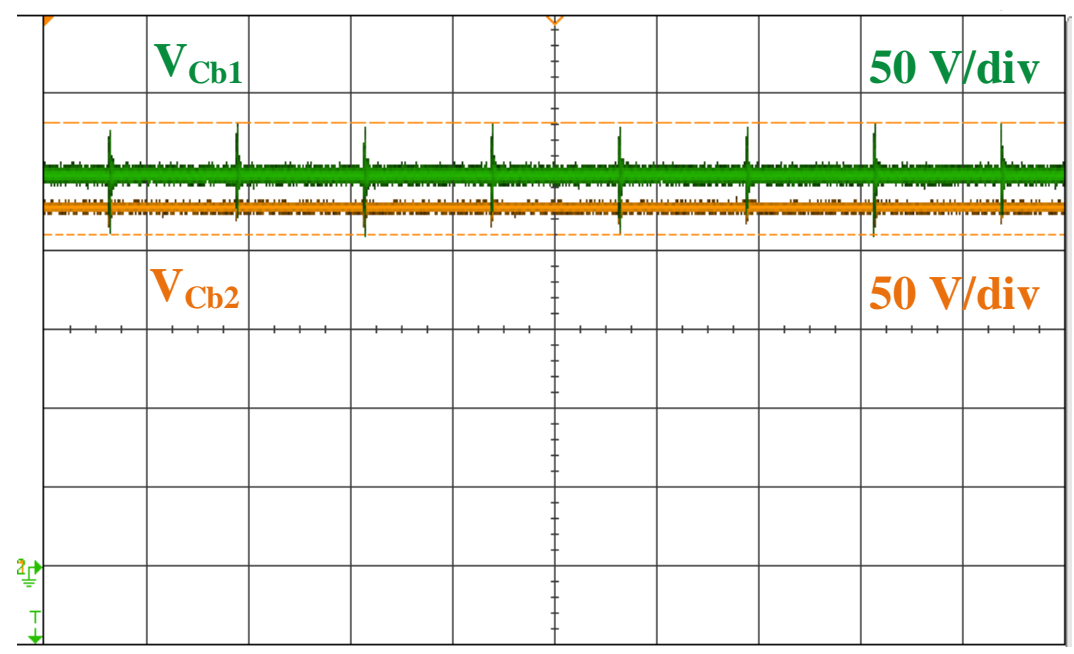

Figure 17. Half-Bridge input capacitors voltage $V_{\mathrm{Cb} 1}$ and $V_{\mathrm{Cb} 2}$ difference, due to the unequal capacitive loads.

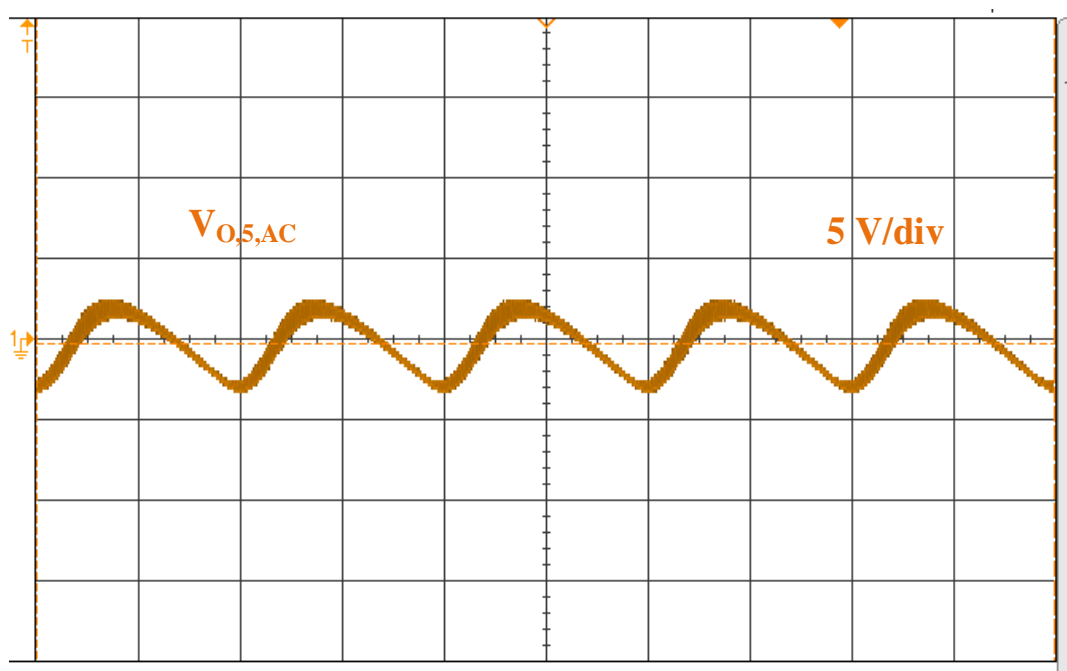

Figure 18. Output voltage ripple $V_{\mathrm{o}, 5, \mathrm{AC}}$ for maximum output voltage.

Later, the consumption of the power converter was measured for different operating modes and the results are shown in Table 3. For these measurements, a $1 \mathrm{M} \Omega$ resistor was connected to the output, in order to emulate the leakage of electrons in case of the PV panel regeneration.

Table 3. Device consumption for different operation modes with a $1 \mathrm{M} \Omega$ resistive load.

\begin{tabular}{ccc}
\hline $\begin{array}{c}\text { Non Loaded Output Voltage } \\
\boldsymbol{V}_{\mathbf{0}, \mathbf{n} \mathbf{l}}(\mathbf{V})\end{array}$ & Input Current $\boldsymbol{I}_{\text {grid }}(\mathbf{m A})$ & Input Power $\boldsymbol{P}_{\text {grid }}(\mathrm{W})$ \\
\hline 0 & 18.5 & 1.8 \\
\hline 370 & 20 & 2.3 \\
\hline 580 & 22.6 & 2.9 \\
\hline 770 & 26.2 & 3.8 \\
\hline 965 & 30.8 & 4.7 \\
\hline
\end{tabular}

Afterwards, measurements on real PV panels followed, to verify the operational principles of the power converter, both for PID creation and regeneration of PV cells. First, the characteristic curves $(\mathrm{P}-\mathrm{V}$ and $\mathrm{I}-\mathrm{V})$ of two $\mathrm{PV}$ panels $\left(\mathrm{PV}_{1}\right.$ and $\left.\mathrm{PV}_{2}\right)$ were measured for 
several days at peak hours of solar radiation. The day with the group of data closest to the nominal ratings was selected. The corresponding curves are shown with dot-dashed lines in Figures 19 and 20. Next, the proposed device is used to artificially create the PID phenomenon on $\mathrm{PV}_{2}$. Reverse polarity was applied continuously for two weeks and then new measurements of the characteristic curves were taken for both panels. The P-V and I-V curves for this case are depicted with dashed lines. Afterwards, right polarity was applied to the $\mathrm{PV}_{2}$ panel, in order to regenerate the PV cells and restore its power production capability. The curves after the regeneration process are depicted with continuous lines in Figures 19 and 20.

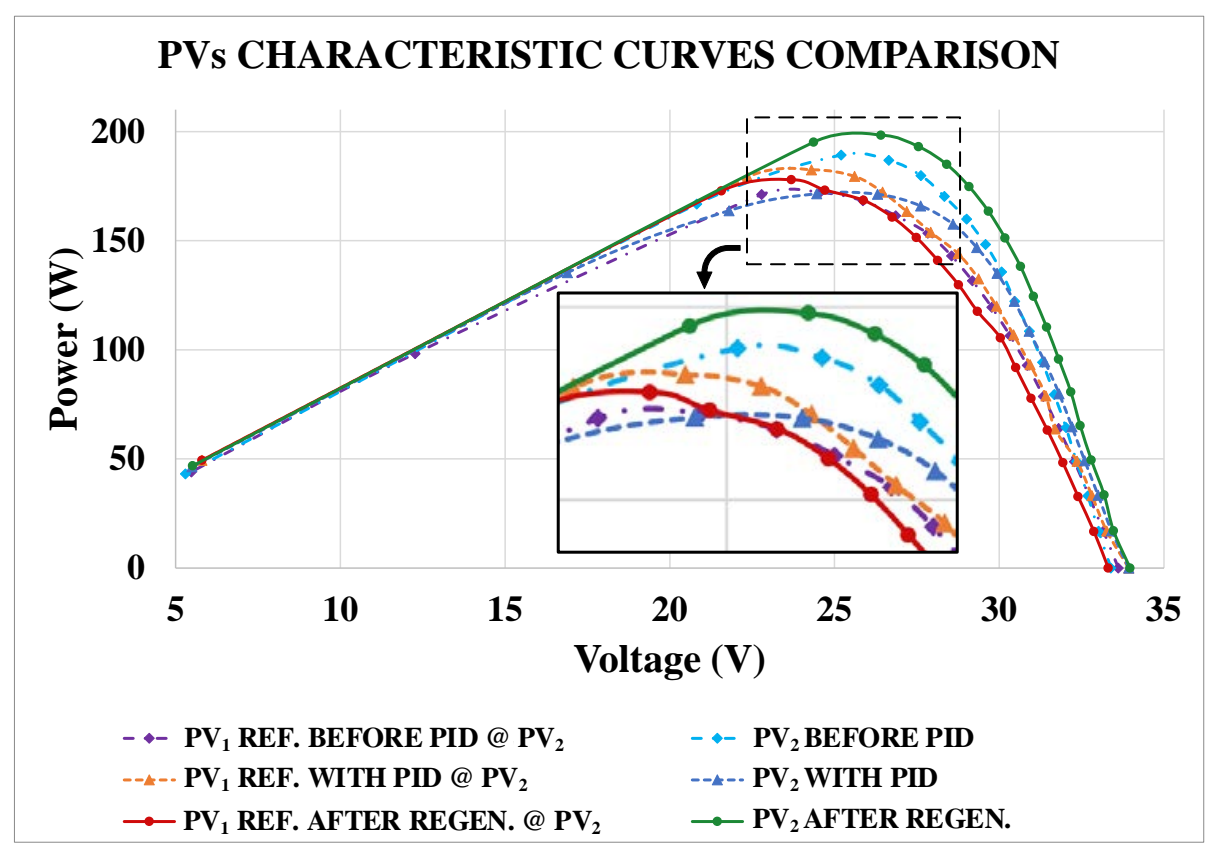

Figure 19. Comparison between the measured $P-V$ characteristic curves of the $\mathrm{PV}_{1}$ (purple) and $P V_{2}$ (cyan) panels before PID (dot-dashed); $\mathrm{PV}_{1}$ (orange) and $\mathrm{PV}_{2}$ (blue) panels with enforced PID (dashed); and $\mathrm{PV}_{1}$ (red) and PV 2 (green) panels after regeneration of the $\mathrm{PV}_{2}$ (continuous).

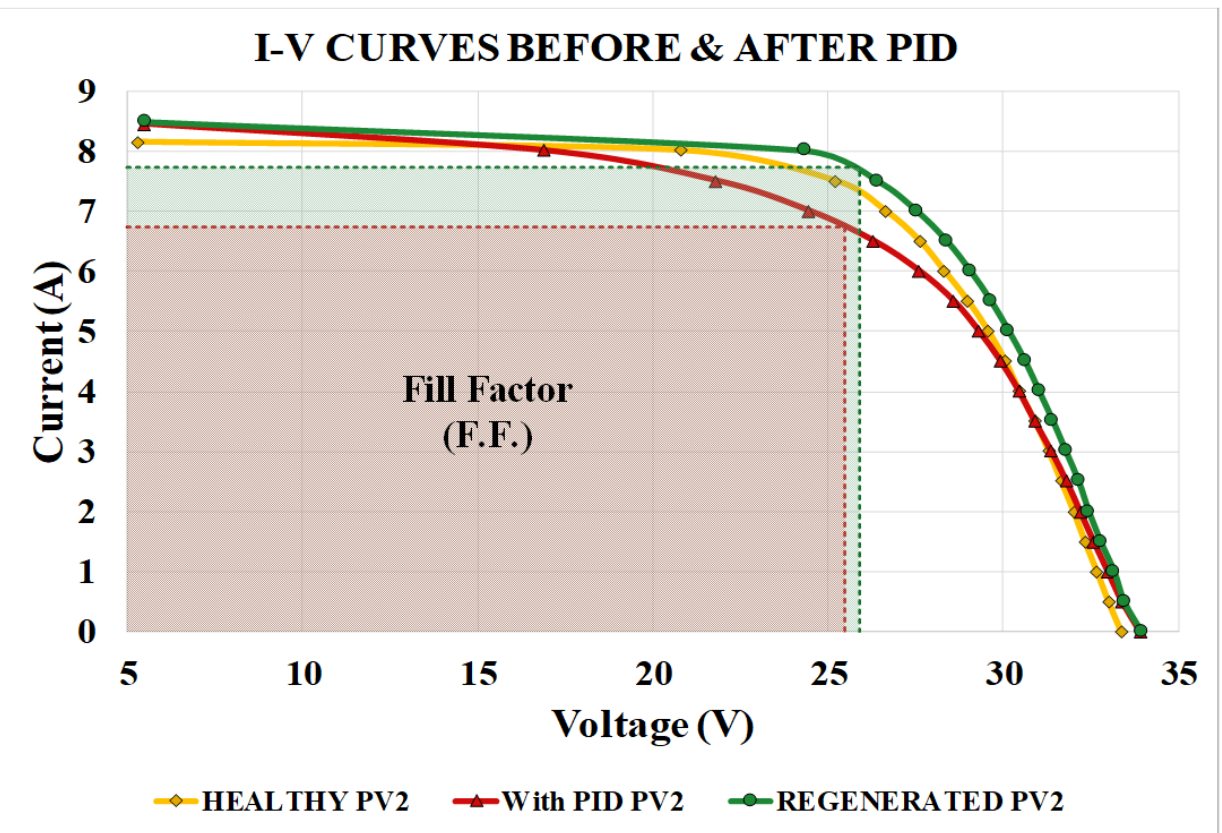

Figure 20. Comparison between the measured I-V characteristic curves of the $\mathrm{PV}_{2}$ panel, before PID, with PID and after regeneration. 
By observing the curves in Figures 19 and 20, important conclusions can be derived. Considering only the results of the panel under test $\mathrm{PV}_{2}$, it is evident that after the enforced PID degradation, the output power generated by the PV is decreased, while after regeneration it is increased even beyond the initial state. However, the results could be ambiguous, since it is impossible for the solar radiation factor to be constant for all the tests. This is the reason why the $\mathrm{PV}_{1}$ was used as the "control panel", to have an indication of the solar radiation.

Before degrading the $\mathrm{PV}_{2}$, its power production was higher than $\mathrm{PV}_{1}$, as expected based on their nominal characteristics. After the PID emulation, the P-I and V-I curves of $\mathrm{PV}_{2}$ were measured lower than before, but the $\mathrm{PV}_{1}$ power production was increased, meaning that there was more solar radiation during those measurements. Therefore, it is absolutely verified that the PID was artificially created in $\mathrm{PV}_{2}$, by polarizing the panel with the proposed power converter.

After regenerating the $\mathrm{PV}_{2}$, its power production was increased with respect to the previous measurement where it was under PID. Meanwhile, the $\mathrm{PV}_{1}$ was measured lower than previously. Hence, the successful regeneration of the degraded PV cells is ensured, because a higher power and larger fill factor (F.F.) was detected compared to the previous case, even with lower solar radiation.

The experimental results at the MPP are shown in Table 4 for the three different states of measurements: the initial healthy state, after enforced PID on $\mathrm{PV}_{2}$ and after regenerating the $\mathrm{PV}_{2}$ panel.

Table 4. Experimental Maximum Power Point (MPP) for the reference PV $\left(\mathrm{PV}_{1}\right)$ and for the PV under test $\left(\mathrm{PV}_{2}\right)$ before and after PID occurrence and with PID regeneration.

\begin{tabular}{ccc}
\hline State of Measurement & Reference PV-PV & PV Under Test-PV \\
\hline PV $_{2}$ without PID & $172.83 \mathrm{~W}$ & $189.26 \mathrm{~W}$ \\
\hline $\mathrm{PV}_{2}$ with enforced PID & $182.48 \mathrm{~W}$ & $171.45 \mathrm{~W}$ \\
\hline $\mathrm{PV}_{2}$ with PID regeneration & $177.9 \mathrm{~W}$ & $198.35 \mathrm{~W}$ \\
\hline
\end{tabular}

\section{Conclusions}

In this paper, a PV regenerating system is proposed, for regenerating PV cells that have been degraded due to the PID phenomenon. The same device can be used to artificially create the PID on PV panels, making it suitable for both industrial and research purposes. The main advantages compared to conventional methods is its small size and low cost, the simplicity of its operation (plug-and-play and no control loop) and its adaptability in systems with different ratings, deriving from the capability of the multiple output voltage levels. The effectiveness of the proposed device and its principle of operation were verified by conducting experiments on PV panels. The PID was successfully created on a PV panel and then the same one was regenerated. The measured characteristic curves proved clear degradation of the power production of the PV cells after PID was enforced and then even greater improvement after the regeneration process was finished. Therefore, the behavioural analysis presented in this paper is confirmed with experimental results.

Author Contributions: Conceptualization, A.M., T.M., S.S. and E.T.; methodology, A.M., T.M., S.S. and E.T.; software, A.M.; validation, A.M., T.M., S.S. and E.T.; formal analysis, A.M., T.M. and S.S.; investigation, A.M., T.M., S.S. and E.T.; resources, A.M., T.M., S.S. and E.T.; data curation, A.M., T.M. and S.S.; writing — original draft preparation, A.M., T.M., S.S. and E.T.; writing-review and editing, A.M., T.M., S.S. and E.T.; visualization, A.M., T.M. and S.S.; supervision, E.T.; project administration, E.T.; funding acquisition, E.T. All authors have read and agreed to the published version of the manuscript.

Funding: This research has been co-financed by the European Union and Greek national funds through the Operational Program Competitiveness, Entrepreneurship and Innovation, under the call RESEARCH-CREATE-INNOVATE (project code: T1EDK—04659). 
Acknowledgments: This research has been co-financed by the European Union and Greek national funds through the Operational Program Competitiveness, Entrepreneurship and Innovation, under the call RESEARCH-CREATE-INNOVATE (project code: T1EDK-04659).

Conflicts of Interest: The authors declare no conflict of interest. The funders had no role in the design of the study; in the collection, analyses, or interpretation of data; in the writing of the manuscript, or in the decision to publish the results.

\section{References}

1. Bose, B.K. Global warming-Energy, environmental pollution and the impact of power electronics. IEEE Ind. Electron. Mag. 2010, 4, 6-17. [CrossRef]

2. European Photovoltaic Industry Association (EPIA). Global Market Outlook for Photovoltaics 2014-2018. 2014. Available online: https://helapco.gr/wp-content/uploads/EPIA_Global_Market_Outlook_for_Photovoltaics_2014-2018_Medium_Res. pdf (accessed on 8 June 2021).

3. Tur, M.R.; Colak, I.; Bayindir, R. Effect of Faults in Solar Panels on Production Rate and Efficiency. In Proceedings of the 2018 International Conference on Smart Grid (icSmartGrid), Nagasaki, Japan, 4-6 December 2018; pp. 287-293.

4. Mertens, K. Photovoltaics: Fundamentals, Technology and Practice, 2nd ed.; John Wiley \& Sons Inc.: Chichester, UK, 2014.

5. Boulhidja, S.; Mellit, A.; Voswinckel, S.; Lughi, V.; Ciocia, A.; Spertino, F.; Massi Pavan, A. Experimental Evidence of PID Effect on CIGS Photovoltaic Modules. Energies 2020, 13, 537. [CrossRef]

6. Understanding Potential Induced Degradation. White Pap.-AE. 2013. Available online: https://www.twentezon.nl/wp-content/ uploads/2015/08/Advanced-Energy_Understanding-Potential-Induced-Dagradation.pdf (accessed on 8 June 2021).

7. Hylský, J.; Strachala, D.; Vyroubal, P.; Pavel, Č.; Vanýsek, P. Effect of negative potential on the extent of PID degradation in photovoltaic power plant in a real operation mode. Microelectron. Reliab. 2018, 85, 12-18. [CrossRef]

8. Bauer, J.; Naumann, V.; Grober, S.; Hagendorf, C.; Schutze, M.; Breitenstein, O. On the mechanism of potential-induced degradation in crystalline silicon solar cells. Phys. Status Solidi-Rapid Res. Lett. 2012, 6, 331-333. [CrossRef]

9. Hoffmann, S.; Koehl, M. Effect of Humidity and Temperature on the Potential-Induced Degradation. Prog. Photovolt. Res. Appl. 2014, 22, 775-783. [CrossRef]

10. Luo, W.; Khoo, Y.S.; Hacke, P.; Naumann, V.; Lausch, D.; Harvey, S.; Singh, J.; Chai, J.; Wang, W.; Aberle, A.; et al. Potential-induced degradation in photovoltaic modules: A critical review. Energy Environ. Sci. 2017, 10, 43-68. [CrossRef]

11. Sporleder, K.; Turek, M.; Schüler, N.; Naumann, V.; Hevisov, D.; Pöblau, C.; Großer, S.; Schulte-Huxel, H.; Bauer, J.; Hagendorf, C. Quick test for reversible and irreversible PID of bifacial PERC solar cells. Sol. Energy Mater. Sol. Cells 2021, 219, 110755. [CrossRef]

12. Christidis, G.C.; Nanakos, A.C.; Tatakis, E.C. Hybrid Discontinuous/Boundary Conduction Mode of Flyback Microinverter for AC-PV Modules. IEEE Trans. Power Electron. 2016, 31, 4195-4205. [CrossRef]

13. Rajeev, M.; Agarwal, V. Analysis and Control of a Novel Transformer-Less Microinverter for PV-Grid Interface. IEEE J. Photovolt. 2018, 8, 1110-1118. [CrossRef]

14. Kapur, J.; Stika, K.M.; Westphal, C.S.; Norwood, J.L.; Hamzavytehrany, B. Prevention of Potential-Induced Degradation With Thin Ionomer Film. IEEE J. Photovolt. 2015, 5, 219-223. [CrossRef]

15. Chen, T.-C.; Kuo, T.-W.; Lin, Y.-L.; Ku, C.-H.; Yang, Z.-P.; Yu, I.-S. Enhancement for Potential-Induced Degradation Resistance of Crystalline Silicon Solar Cells via Anti-Reflection Coating by Industrial PECVD Methods. Coatings 2018, 8, 418. [CrossRef]

16. Finsterle, T.; Černá, L.; Hrzina, P.; Rokusek, D.; Benda, V. Diagnostics of PID Early Stage in PV Systems. Energies 2021, 14, 2155. [CrossRef]

17. Swanson, R.M.; Cudzinovic, M.; DeCeuster, D.; Desai, V. The surface polarization effect in high-efficiency silicon solar cells. In Proceedings of the 15th International PVSEC, Shanghai, China, 10-15 October 2005; pp. 410-411.

18. PIDbox Mini-Ilumen. Ilumen. 2021. Available online: https://www.ilumen.be/en/all-products/pid-box-mini/ (accessed on 24 June 2021).

19. Vigdu.com. 2021. Available online: https://www.vigdu.com/anti-pid-residential-systems (accessed on 24 June 2021).

20. PID Technology-You Have PID Issues? Take the PADCON Protection and Solution for This Problem.-PADCON-Future Technologies. Padcon.com. 2021. Available online: https://www.padcon.com/en/effective_PID_technology_for_pv_systems. html (accessed on 24 June 2021).

21. Liu, H.-C.; Huang, C.T.; Lee, W.K.; Lin, M.-H. High Voltage Stress Impact on P Type Crystalline Silicon PV Module. Energy Power Eng. 2013, 5, 455-458. [CrossRef]

22. Kobougias, I.C.; Tatakis, E.C. Optimal Design of a Half-Wave Cockcroft-Walton Voltage Multiplier with Minimum Total Capacitance. IEEE Trans. Power Electron. 2010, 9, 2460-2468. [CrossRef]

23. Rashid, M.H. Power Electronics Handbook: Devices Circuits and Application, 3rd ed.; Elsevier: Burlington, MA, USA, 2011.

24. VICOR. Designing a BCM Pre-Charge Circuit. Application Note AN:037. 2017. Available online: http:/ / www.vicorpower.com/ documents/application_notes/an_Designing_BCM_Precharge_Circuit.pdf (accessed on 8 June 2021). 